\title{
Effects of Vitamin D Supplementation on Lipid Profile and Plasma Glucose of Preeclamptic Women in Ibadan, Nigeria
}

\author{
Ayobola Abimbola Sonuga ${ }^{1 *}$, Modupe Fisayo Asaolu2, Oyebola Oluwagbemiga Sonuga ${ }^{3}$ \\ ${ }^{1}$ Department of Science Laboratory Technology, Ekiti State University, Ekiti, Nigeria \\ ${ }^{2}$ Department of Biochemistry, Ekiti State University, Ekiti, Nigeria \\ ${ }^{3}$ Department of Chemical Pathology, University College Hospital, Ibadan, Nigeria \\ Email: *ayobolasonuga@gmail.com
}

How to cite this paper: Sonuga, A.A., Asaolu, M.F. and Sonuga, O.O. (2018) Effects of Vitamin D Supplementation on Lipid Profile and Plasma Glucose of Preeclamptic Women in Ibadan, Nigeria. Open Access Library Journal, 5: e4410.

https://doi.org/10.4236/oalib.1104410

Received: February 5, 2018

Accepted: March 4, 2018

Published: March 7, 2018

Copyright $\odot 2018$ by authors and Open Access Library Inc.

This work is licensed under the Creative Commons Attribution International License (CC BY 4.0).

http://creativecommons.org/licenses/by/4.0/

\begin{abstract}
Biochemical metabolites are implicated in preeclampsia, which include elevated plasma concentration of Triglycerides (TG), Low Density Lipoprotein Cholesterol (LDLC), total lipids and reduced High Density Lipoprotein Cholesterol (HDLC) concentrations and significant reductions in fasting plasma glucose, and serum insulin homeostasis model of assessment. Vitamin D supplementation seems to be a possible target for intervention and possible improved pregnancy outcomes in preeclampsia. Therefore, this study aimed at determining the effects of Vitamin D supplementation on the Lipid Profile, and random plasma glucose levels of preeclamptic women in Ibadan, Nigeria. This interventional study was carried out at the Antenatal clinic of Obstetrics and Gynecology Departments of University College Hospital Ibadan and Adeoyo Maternity Clinic, Yemetu, Ibadan, Nigeria. 120 pregnant women aged 18 to 35 were recruited; 40 normotensive pregnant women served as control; 40 randomly chosen preeclamptic women were placed on oral vitamin D supplement of $1000 \mathrm{IU} /$ day for 8 weeks and 40 preeclamptic women were given no supplement. Blood samples were taken at study baseline (22 weeks), after 8 weeks of supplementation ( $3^{\text {rd }}$ trimester) and 3 to 5 days postpartum in all groups to quantify serum vitamin $\mathrm{D}$, random glucose and Lipid profile. Vitamin D was quantified by Enzyme Linked Immunosorbent Assay (ELISA), glucose status by glucose oxidase method and lipid profile by standard methods. Statistical analysis was performed using Statistical Package for Social Sciences (SPSS) soft version 17.0 and subjected to One way analysis of Variance (ANOVA) and Student's $\mathrm{t}$ test. Results showed a significant increase ( $p<$ $0.05)$ in levels of TG, LDLC, random plasma glucose and a decrease $(p<0.05)$ in HDLC levels in the preeclamptic groups when compared with normoten-
\end{abstract}


sive women in second and third trimester. After vitamin $\mathrm{D}$ supplementation, there was a significant reduction $(p<0.05)$ in Total Cholesterol (TC), TG, LDLC levels and an increase in HDLC $(p<0.05)(4.49 \pm 0.38,1.51 \pm 0.22,3.45$ $\pm 0.57,1.87 \pm 0.29)$ vs. $(5.96 \pm 0.49,2.30 \pm 0.20,5.90 \pm 0.36,1.07 \pm 0.28)$ respectively. Random plasma glucose level was reduced $(5.7 \pm 0.5$ vs. $6.01 \pm$ $0.43)$, though not statistically significant $(p>0.05)$. Vitamin D supplementation is important in ameliorating dyslipidemia associated with preeclampsia.

\section{Subject Areas}

Biochemistry

\section{Keywords}

Vitamin D, Supplementation, Lipid profile, Glucose, Preeclampsia

\section{Introduction}

Hypertensive disorders of pregnancy, including gestational hypertension, preeclampsia (PE), and eclampsia, are among the major complications that account for approximately $14 \%$ of maternal mortality worldwide [1]. Preeclampsia is the onset of a new episode of hypertension during pregnancy (with persistent diastolic blood pressure $>90 \mathrm{~mm} \mathrm{Hg}$ ) with the occurrence of substantial proteinuria $(>0.3 \mathrm{~g} / 24 \mathrm{~h})$ [2]. Though abnormal placentation exists from very early stages of the pregnancy, hypertension and proteinuria usually surface at 20 weeks and above of pregnancy [2]. The complications of preeclampsia include eclampsia, disseminated intravascular coagulation and the HELLP syndrome (hemolytic anemia, elevated liver enzymes, and low platelets [3], hemorrhagic stroke, liver damage and dysfunction [4]), intrauterine growth restriction (IUGR) and fetal death [5]. Vitamin D3, or cholecalciferol, is formed endogenously when 7-dehydrocholesterol in keratinocytes is converted to a seco-steroid pro-hormone by ultraviolet light. Then two successive hydroxylations at the 25 position to form 25-hydroxyvitamin D [25(OH)D], which occurs in the liver, and second to form the active hormonal metabolite 1,25-dihydroxyvitamin $\mathrm{D}$ $[1,25(\mathrm{OH}) 2 \mathrm{D}]$, also called calcitriol, which takes place in the kidney. Calcitriol binds to its nuclear receptor and modulates gene expression for calcium absorption in the intestine. Vitamin D status is determined by the measurement of its circulating form, 25-hydroxyvitamin D [25(OH)D] [6]. Vitamin D plays important role in modulating pro-inflammatory responses and decreasing oxidative stress in preeclampsia, promoting angiogenesis through VEGF and gene modulation, and decreasing blood pressure through the renin-angiotensin system (RAS) [7] [8].

In previous studies, hypovitaminosis $\mathrm{D}$ has been associated with preeclampsia [9] [10], and early pregnancy dyslipidemia associated with an increased risk of preeclampsia [11]. Elevated plasma lipid and lipoprotein may induce endothelial 
dysfunction secondary to oxidative stress. Researchers have also noted that dyslipidemia may impair trophoblast invasion thus contributing to pathophysiologic events that lead to the development of preeclampsia [12]. Low levels of HDL-Cholesterol may affect its ability to transport cholesterol from peripheral tissues to the liver where it can be excreted. The activation of lipoprotein which releases fatty acids is also altered. Triglyceride rich lipoprotein has a prothrombotic activity [13] and increase in triglycerides might shift the pattern of LDL subclass towards disproportionate increase in smaller denser, more allergenic LDL particles. Dyslipidemia might not just be a characteristic feature of preeclampsia but one of the causative factors predisposing to preeclampsia. A study involving about 23,000 pregnant women observed that taking a vitamin D supplement of $600-800 \mathrm{IU} /$ day reduced the chances of developing preeclampsia compared with women taking no supplement [14]. Vitamin D has also been shown to correlate with $\beta$-cell function and insulin resistance in humans [15] and abnormal glucose tolerance [16].

A research work reported that consumption of $500 \mathrm{mg}$ carbonate calcium plus 200 IU vitamin D3 in women with preeclampsia for 9 weeks resulted in decreased FPG and serum triglycerides levels as compared to the placebo group, but could not affect serum total-, HDL-, LDL-cholesterol levels [17]. Another study observed that taking combined cholecalciferol and calcium supplements, compared to placebo, in a similar study led to significant reductions in fasting plasma glucose (FPG) and increased serum high-density lipoprotein (HDL)-cholesterol [18].

Till date, few intervention studies have been reported and the findings are inconsistent. It is therefore important to supplement preeclamptic women in this region with vitamin $\mathrm{D}$ and investigate the effect of this supplementation on their lipid profile and glucose metabolism.

\section{Material and Methods}

\subsection{Study Design}

This is an interventional study in which subjects were recruited from antenatal clinic of Obstetrics and Gynecology Departments of University College Hospital Ibadan and Adeoyo Maternity Clinic, Yemetu, Ibadan, Nigeria. Ethical Clearance was given by Ethical Committee of The University College Hospital and Oyo State Ethical committee, Nigeria. The study population was between the ages of 18 and 35 years randomly grouped into three:

Group A: 40 Normotensive pregnant women,

Group B: 40 Nulliparious preeclamptic women (without Vitamin D supplement),

Group C: 40 Nulliparious preeclamptic women (on Vitamin D supplement).

Participants considered to be preeclamptic were subjects with elevated blood pressure, $\mathrm{BP} \geq 140 / 90 \mathrm{mmHg}$ twice and significant proteinuria of at least $300 \mathrm{mg}$ in a 24 -hour collection of urine, or a urine dipstick result of $1+$ or greater, ac- 
cording to the International Society for the Study of Preeclampsia. Blood pressure, Weight, Height were taken and body mass index calculated in all of the pregnant women at their visit at 22 weeks of pregnancy, using a standard analog sphygmomanometer, weighing balance and meter rule respectively. Questionnaires on socio demographic information, medical history, health behavior, diets and lifestyle were issued to them and informed consent form duly signed. Blood and urine specimens were taken randomly from each subjects starting from the 22nd week of gestation for analysis of Vitamin D, Random Blood Glucose and Lipid Profile.

Subjects with preeclampsia were randomly grouped into Group B and C. The Group B were not supplemented, while 40 randomly chosen preclamptic women, were given oral vitamin D supplements of 1000 IU per day for the duration of 8 weeks from time of recruitment (22 weeks). They were followed up during this supplementation period to ensure compliance. Blood samples were collected again from all the groups after 8 weeks of recruitment (Group A and B) at $3^{\text {rd }}$ trimester and supplementation (Group C), and 3 to five days postpartum. Samples for the analysis of vitamin D and Lipid Profile were stored at $-80^{\circ} \mathrm{C}$ at Institute for advanced Medical Research and Training (IMRAT) in University of Ibadan before analysis. The random blood glucose was evaluated immediately after collection of samples from each participants and results properly documented.

\subsection{Sample Collection}

$10 \mathrm{mls}$ of venous blood was collected from each participants thrice (at 22 weeks, 30 weeks and postpartum) after issuing them the informed consent form. $5 \mathrm{mls}$ into Plain bottle, blood was allowed to clot, centrifuged and serum separated for analysis of Vitamin D, $3 \mathrm{mls}$ into EDTA bottle, centrifuged and plasma separated for analysis of Lipid profile and $2 \mathrm{mls}$ for random plasma glucose. Spot urine was collected for assessment of protein using urine dipstick.

\subsection{Assessment of Anthropometric Measures}

Anthropometric measurements were assessed at baseline (22 weeks of pregnancy). Body weight was taken without shoes and in a minimal clothing state by the use of a bathroom scale to the nearest $0.1 \mathrm{~kg}$. Height was measured using a non-stretched tape measure to the nearest $0.1 \mathrm{~cm}$. BMI was calculated as weight in $\mathrm{kg}$ divided by height in meters squared.

\subsection{Biochemical Assessment}

Vitamin $\mathrm{D}$ by Enzyme Linked Immunosorbent Assay as described by [19].

Serum vitamin D status was defined as (in $\mathrm{ng} / \mathrm{ml})$ : deficient $(<10 \mathrm{ng} / \mathrm{ml})$, Insufficient (10 ng/ml - $30 \mathrm{ng} / \mathrm{ml}$ ), Sufficient (30 ng/ml - $100 \mathrm{ng} / \mathrm{ml}$ ), according to Calbiotech Inc. 25(OH) Vitamin D Elisa kit used for this analysis.

Glucose status: By assessing plasma glucose, using glucose oxidase method described by [20]. 


\section{Lipid profile:}

Estimation of Plasma Cholesterol: Plasma Total cholesterol was analysed by the cholesterol CHOD-PAP method which is an enzymatic end point method [21].

Estimation of Serum HD-LC: HDL in the sample was separated by precipitation through the procedure adopted by [22].

Estimation of Serum Triglycerides: GPO-PAP method of Randox diagnostic kit [23].

Calculation of LDL-C and VLDL-C: VLDL-C level in serum was derived by dividing serum triglycerides by 5 and LDL-C was obtained using Friedwald's formula [24]:

$$
\begin{aligned}
& \text { LDL-cholesterol }(\mathrm{mmol} / \mathrm{l}) \\
& =\text { Total Cholesterol }- \text { Triacylglycerol-HDL-cholesterol }
\end{aligned}
$$

\subsection{Statistical Analysis}

Statistical analysis was performed using Statistical Package for Social Sciences (SPSS) soft version 20.0. All data were expressed as mean and SD (Standard deviation). Test of significance for the differences between the means of two groups was assessed by T-test. ANOVA was used to compare the 3 groups. Data were analyzed at $95 \%$ confidence interval and P-values less than $0.05(p<0.05)$ were considered statistically significant.

\section{Results}

The mean age of the normotensive and preeclamptic women was not statistically different $(P>0.05)$, while the systolic blood pressure, diastolic blood pressure and BMI of the preeclamptic groups were significantly higher than the normotensive group $(P<0.05)$. The gestation age at labour was significantly lower $(P<$ $0.05)$ in preeclamptic groups when compared with the normotensive group. However vitamin D supplementation had no effect on gestation age at labour (Table 1).

There was a statistically significant decrease in serum Vit. D levels in the preeclamptic group (Group B and C) in $2^{\text {nd }}, 3^{\text {rd }}$ trimester, and 3 - 5 days postpartum when compared to the normotensive group (Table 2).

There was a significant increase in Vitamin D levels after supplementation $\left(3^{\text {rd }}\right.$ trimester and postpartum) in Group C.

The mean plasma glucose level was significantly higher in the preeclamptic groups (Group B and C) at $2^{\text {nd }}, 3^{\text {rd }}$ trimester and postpartum when compared with control.

The mean plasma glucose level was not statistically different in $2^{\text {nd }}$, third trimester, and postpartum in the control group while in Group B, there was a reduction in glucose levels at postpartum, when compared with third trimester.

The mean plasma glucose levels of the supplemented group was reduced after supplementation but was not statistically significant. 
Table 1. Baseline Characteristics of Normotensive pregnant women (Group A), Preeclamptic women without supplement (Group B), Preeclamptic women on supplement (Group C).

\begin{tabular}{cccc}
\hline Variables & $\begin{array}{c}\text { Control } \\
(\mathrm{n}=40)\end{array}$ & $\begin{array}{c}\text { PE without } \\
\text { Supplement } \\
(\mathrm{n}=40)\end{array}$ & $\begin{array}{c}\text { PE with } \\
\text { supplement } \\
(\mathrm{n}=40)\end{array}$ \\
\hline Age & $32.1 \pm 4.4^{\mathrm{a}}$ & $31.4 \pm 3.3^{\mathrm{a}}$ & $33.5 \pm 4.0^{\mathrm{a}}$ \\
Systolic Blood Pressure & $108 \pm 5.5^{\mathrm{a}}$ & $149.8 \pm 15.8^{\mathrm{b}}$ & $148 \pm 11.0^{\mathrm{b}}$ \\
Diastolic Blood Pressure & $75.3 \pm 7.5^{\mathrm{a}}$ & $91.9 \pm 13.2^{\mathrm{b}}$ & $90.9 \pm 9.9^{\mathrm{b}}$ \\
Body Mass Index (BMI) & $24.7 \pm 0.9^{\mathrm{a}}$ & $29.4 \pm 4.6^{\mathrm{b}}$ & $30.0 \pm 2.8^{\mathrm{b}}$ \\
Gestation at Labour (Wks) & $38 \pm 0.8^{\mathrm{a}}$ & $36.2 \pm 1.9^{\mathrm{b}}$ & $36.6 \pm 2.6^{\mathrm{b}}$ \\
\hline
\end{tabular}

Values of the same subscript within the same column are not statistically different at $(p>0.05)$ between the control and case group, while values with different subscripts are significantly different at $(p<0.05)$.

Table 2. Shows maternal levels of Vitamin D (Vit. D), Glucose and Lipid profile in 2nd, third trimester and postpartum (PP) of Normotensive pregnant women (Group A), Preeclamptic women without supplement (Group B), Preeclamptic women on supplement (Group C).

\begin{tabular}{|c|c|c|c|c|}
\hline & & $\begin{array}{l}\text { Control } \\
(\mathrm{n}=40)\end{array}$ & $\begin{array}{l}\text { PE without } \\
\text { supplement } \\
\quad(\mathrm{n}=40)\end{array}$ & $\begin{array}{l}\text { PE with } \\
\text { supplement } \\
(\mathrm{n}=40)\end{array}$ \\
\hline \multirow{3}{*}{$\begin{array}{l}\text { Vit. D } \\
\text { (ng/ml) }\end{array}$} & $2^{\text {nd }}$ trimester & $37.59 \pm 6.27^{\mathrm{a}}$ & $24.0 \pm 4.64^{\mathrm{b}}$ & $25.9 \pm 7.2^{b}$ \\
\hline & $3^{\text {rd }}$ trimester & $34.44 \pm 3.85^{c}$ & $23.8 \pm 3.85^{\mathrm{b}}$ & $32.81 \pm 1.4^{\mathrm{d}}$ \\
\hline & Postpartum & $33.12 \pm 1.21^{\mathrm{c}}$ & $21.7 \pm 5.59^{\mathrm{d}}$ & $35.16 \pm 4.3^{\mathrm{a}}$ \\
\hline \multirow{3}{*}{$\begin{array}{c}\text { Glucose } \\
(\mathrm{mmol} / \mathrm{l})\end{array}$} & $2^{\text {nd }}$ trimester & $4.41 \pm 0.73^{\mathrm{a}}$ & $5.92 \pm 0.88^{\mathrm{b}}$ & $6.01 \pm 0.43^{\mathrm{b}}$ \\
\hline & $3^{\text {rd }}$ trimester & $4.38 \pm 1.13^{\mathrm{a}}$ & $5.93 \pm 1.32^{\mathrm{b}}$ & $5.71 \pm 0.5^{\mathrm{b}}$ \\
\hline & Postpartum & $4.35 \pm 0.68^{\mathrm{a}}$ & $5.51 \pm 0.82^{\mathrm{b}}$ & $5.41 \pm 0.91^{b}$ \\
\hline \multirow{3}{*}{$\begin{array}{l}\text { T. Chol. } \\
\text { (mmol/l) }\end{array}$} & $2^{\text {nd }}$ trimester & $5.24 \pm 0.62^{\mathrm{a}}$ & $5.88 \pm 2.10^{\mathrm{a}}$ & $5.96 \pm 0.49^{\mathrm{a}}$ \\
\hline & $3^{\text {rd }}$ trimester & $5.29 \pm 0.77^{\mathrm{a}}$ & $6.17 \pm 1.78^{\mathrm{b}}$ & $4.49 \pm 0.38^{\mathrm{c}}$ \\
\hline & Postpartum & $5.07 \pm 0.78^{\mathrm{a}}$ & $7.14 \pm 1.09^{\mathrm{b}}$ & $4.52 \pm 0.51^{c}$ \\
\hline \multirow{3}{*}{$\begin{array}{c}\text { TG } \\
(\mathrm{mmol} / \mathrm{l})\end{array}$} & $2^{\text {nd }}$ trimester & $1.19 \pm 0.13^{\mathrm{a}}$ & $2.11 \pm 0.23^{\mathrm{b}}$ & $2.30 \pm 0.20^{\mathrm{b}}$ \\
\hline & $3^{\text {rd }}$ trimester & $1.21 \pm 0.17^{\mathrm{a}}$ & $2.29 \pm 0.24^{\mathrm{b}}$ & $1.51 \pm 0.22^{\mathrm{c}}$ \\
\hline & Postpartum & $1.11 \pm 0.27^{\mathrm{a}}$ & $2.49 \pm 0.3^{\mathrm{b}}$ & $1.08 \pm 0.37^{\mathrm{a}}$ \\
\hline \multirow{3}{*}{$\begin{array}{c}\text { HDLC } \\
(\mathrm{mmol} / \mathrm{l})\end{array}$} & $2^{\text {nd }}$ trimester & $1.60 \pm 0.43^{\mathrm{a}}$ & $1.17 \pm 0.37^{\mathrm{b}}$ & $1.07 \pm 0.28^{\mathrm{b}}$ \\
\hline & $3^{\text {rd }}$ trimester & $1.50 \pm 0.32^{\mathrm{a}}$ & $1.09 \pm 0.38^{b}$ & $1.87 \pm 0.29^{c}$ \\
\hline & Postpartum & $1.69 \pm 0.52^{\mathrm{a}}$ & $1.24 \pm 0.28^{\mathrm{b}}$ & $1.99 \pm 0.54^{c}$ \\
\hline \multirow{3}{*}{$\begin{array}{c}\text { LDLC } \\
(\mathrm{mmol} / \mathrm{l})\end{array}$} & $2^{\text {nd }}$ trimester & $4.12 \pm 0.66^{\mathrm{a}}$ & $5.18 \pm 2.09^{\mathrm{b}}$ & $5.90 \pm 0.36^{\mathrm{b}}$ \\
\hline & $3^{\text {rd }}$ trimester & $3.64 \pm 0.84^{\mathrm{b}}$ & $5.93 \pm 1.83^{c}$ & $3.45 \pm 0.57^{\mathrm{a}}$ \\
\hline & Postpartum & $3.41 \pm 0.73^{\mathrm{b}}$ & $6.84 \pm 1.01^{\mathrm{d}}$ & $3.40 \pm 0.67^{\mathrm{a}}$ \\
\hline
\end{tabular}

Values of the same subscript within the same column are not statistically different at $(p>0.05)$ between the control and case group, while values with different subscripts are significantly different at $(p<0.05)$. Vit. D: Vitamin D, T. Chol: Total Cholesterol, TG: Triglycerides, HDLC: High Density Lipoprotein Cholesterol, LDLC: Low Density Lipoprotein Cholesterol. 
A significant increase occurred in the levels of TG and LDLC levels while there was a significant decrease in HDLC levels, in the preeclamptic groups (Group B and C) at $2^{\text {nd }}$ trimester when compared with controls. No significant difference occurred in the levels of TC levels at $2^{\text {nd }}$ trimester in the three groups. There was no significant difference in TC, TG, and HDLC levels at $2^{\text {nd }}, 3^{\text {rd }}$ trimester and postpartum in the control group, while a significant decrease occurred in LDLC in the $3^{\text {rd }}$ trimester which was not statistically different from levels at postpartum.

After supplementation in the $3^{\text {rd }}$ trimester, there was a significant reduction in TC, TG, LDLC levels in group C, the levels of LDLC and TC postpartumly were not statistically different from third trimester while a significant increase occurred in HDLC levels which was not statistically different at postpartum. TG was significantly reduced at postpartum in the supplemented group.

\section{Discussion}

The significant increase in the levels of TG, LDLC levels and decreased HDLC levels, in the preeclamptic groups in $2^{\text {nd }}$, third trimester and postpartum as observed in this study is in accordance with the work of [25] [26]. Dyslipidemia, which refers to raised levels of TC, TG and LDL-C and decreased levels of HDL-C may impair trophoblastic invasion thereby contributing to pathophysiological events that lead to the development of preeclampsia [12]. There are several mechanisms by which dyslipidemia may contribute to preeclampsia, according to Mikhail increased serum triglyceride levels in pregnancy leads to increased endothelial accumulation, which may result in endothelial dysfunction [27]. Hypertriglyceridemic dyslipidemia could also lead to development of atherotic changes in the spiral arteries as well as promote prothrombotic mechanisms [28]. Increased triglycerides in preeclampsia are likely to be deposited in uterine spiral arteries and contribute to the endothelial dysfunction characteristic of preeclampsia, through generation of small, dense LDL [29] [30]. Previous work has shown that LDL increases artery sensitivity to presser agents and inhibits endothelial-dependant vasodilatation. This may be a potential contributor to endothelial cell dysfunction as seen in preeclampsia [31]. Low HDL-C in preeclampsia can be as a result of insulin resistance and hypoestrogenemia [5] [32].

This study also observed that after supplementation with $1000 \mathrm{IU} /$ day of Vit $\mathrm{D}$, there was a significant reduction in TC, TG, LDLC levels in the preeclamptic group, while a significant increase occurred in HDLC levels and progressed postpartumly. This supports the findings of [33] [34], suggesting that vitamin D may directly affect the regulation of lipids. Vitamin D insufficiency as observed in this study, may be associated with impaired b-cell function and insulin resistance which could affect lipoprotein metabolism and lead to an increase in TG level and a decrease in HDL-C level. 25 hydroxyvitamin $\mathrm{D}(25(\mathrm{OH}) \mathrm{D})$ has been suggested to be involved in lipid metabolism which help to increase intestinal calcium absorption and thus the amount of absorbed calcium. An increased calcium content in the gut as a result of vitamin D supplementation increases the 
calcium binding of bile acids, and increases the conversion of cholesterol to bile acids, and cholesterol excretion [35]. Intracellular calcium in the liver can stimulate Microsomal Triglycerides Transfer Protein (MTP) which plays an important role in the formation and secretion of VLDL and thereby decrease serum triglycerides levels [36]. Therefore, as serum vitamin D levels increases, this can invariably reduce the levels of TC, LDLC in circulation and indirectly improve the endothelium function and prevent prothrombotic activities, thereby improving pregnancy outcome in preeclampsia. Other studies have proved that higher concentrations of 25(OH)D suppress serum PTH levels and since high level of parathyroid hormone (PTH) could result in increase in TG levels, vitamin D could influence TG concentrations by regulating PTH levels [37].

A significant increase in random serum glucose in $2^{\text {nd }}$ and $3^{\text {rd }}$ trimester in preeclamptics as compared to the normotensives was observed in this study and a slight decrease in serum glucose after supplementation in the preeclamptics though not statistically significant was observed. Some studies have demonstrated an inverse relationship between serum vitamin $\mathrm{D}$ levels with fasting glucose [38] [39]. Anti-inflammatory state is related with insulin resistance as seen in preeclampsia. These cytokines, TNF- $\alpha$ and IL-6, are known to be released from adipose tissue [40] during inflammation and result in induction of insulin resistance and increased FPG [41]. Vitamin D has anti-inflammatory properties and suppresses the release of TNF- $\alpha$ and IL-6 [42] which might indirectly increase insulin sensitivity and then decrease serum glucose. Adequate vitamin D can also aid in the suppression of chronic inflammation and increased expression of the insulin receptor and/or proteins of the insulin signaling cascade [43]. The insignificant decrease in glucose level after vitamin D supplementation might be because random plasma glucose was used in this study and not fasting glucose.

\section{Conclusion and Recommendation}

Dyslipidemia and impaired glucose metabolism is associated with an increased risk of preeclampsia. There is a link between vitamin D insufficiency, impaired lipid and glucose metabolism found in preeclampsia. Thus, this study has observed that an increase in serum vitamin D through prompt supplementation in preeclamptic women can help improve lipoprotein metabolism, thereby improving pregnancy outcome.

Vitamin D remains very relevant in cardiovascular diseases especially preeclampsia, and supplementation should be encouraged in preeclamptic women as early as first trimester till delivery.

\section{Acknowledgements}

We acknowledge all the staffs of the Department of Biochemistry and Department of Science Laboratory Technology, Ekiti State University, Ado Ekiti, Nigeria, for assisting in the completion of this research work. 


\section{Conflict of Interest}

No conflict of interest exists.

\section{Authors' Contributions}

This work was carried out in collaboration between all authors. Author AAS designed the study, managed the literature searches, performed the statistical analysis, wrote the protocol and the first draft of the manuscript. Author MFA supervised the research work and approved the final manuscript. Author OOS supervised sample collection, supplementation and analyzed all the samples. All authors read and approved the final manuscript.

\section{Consent}

All authors declare that written informed consent was obtained from the patients before sample collection.

\section{Ethical Approval}

All authors hereby declare that ethical clearance was given by Joint Ethical Committee of the College of Medicine and the University College Hospital, Ibadan Nigeria.

\section{References}

[1] World Health Organization. (2016) Fact Sheet-Maternal Mortality.

[2] Steegers, E.A., von Dadelszen, P., Duvekot, J.J. and Pijnenborg, R. (2010) Pre-Eclampsia. The Lancet, 376, 631-644. https://doi.org/10.1016/S0140-6736(10)60279-6

[3] Duley, L. (2009) The Global Impact of Pre-Eclampsia and Eclampsia. Seminars in Perinatology, 33, 130-137. https://doi.org/10.1053/j.semperi.2009.02.010

[4] Arulkumaran, N. and Lightstone, L. (2013) Severe Pre-Eclampsia and Hypertensive Crises. Best Practice \& Research Clinical Obstetrics \& Gynaecology, 27, 877-884. https://doi.org/10.1016/j.bpobgyn.2013.07.003

[5] Srinivas, S.K., Edlow, A.G., Neff, P.M., Sammel, M.D., Andrela, C.M. and Elovitz, M.A. (2009) Rethinking IUGR in Preeclampsia: Dependent or Independent of Maternal Hypertension? Journal of Perinatology: Official Journal of the California Perinatal Association, 29, 680-684.

[6] Hollis, B.W. and Wagner, C.L. (2004) Assessment of Dietary Vitamin D Requirements during Pregnancy and Lactation. American Journal of Clinical Nutrition, 79, 717-726.

[7] Cardus, A., Parisi, E., Gallego, C., Aldea, M., Fernandez, E. and Valdivielso, J.M. (2006) 1,25-Dihydroxyvitamin D3 Stimulates Vascular Smooth Muscle Cell Proliferation through a VEGF-Mediated Pathway. Kidney International, 69, 1377-1384. https://doi.org/10.1038/sj.ki.5000304

[8] Evans, K.N., Bulmer, J.N., Kilby, M.D. and Hewison, M. (2004) Vitamin D and Placental Decidual Function. Journal of the Society for Gynecologic Investigation, 11, 263-271. https://doi.org/10.1016/j.jsgi.2004.02.002

[9] Sonuga, A.A., Asaolu, M.F. and Sonuga, O.O. (2017) Serum Vitamin D Status in 
Women with Preeclampsia in Ibadan, Nigeria-A Case-Control Study. Journal of Applied Life Sciences International, 14, 1-6. https://doi.org/10.9734/JALSI/2017/37632

[10] Baker, A.M., Haeri, S., Camargo, C.A., et al. (2010) A Nested Case-Control Study of Midgestation Vitamin D Deficiency and Risk of Severe Preeclampsia. The Journal of Clinical Endocrinology and Metabolism, 95, 5105-5109. https://doi.org/10.1210/jc.2010-0996

[11] Wakatsuki, A., Ikenoue, N., Okatani, Y., Shinohara, K. and Fukaya, T. (2000) Lipoprotein Particles in Preeclamsia: Sucsceptibility to Oxidative Modification. Obstetrics \& Gynecology, 96, 55.

[12] Sachdeva, P.D., Patel, B.G. and Bhatt, M.V. (2011) A Study of Incidence and Management of Pregnancy Induced Hypertension in Central Gujarat, India. International Journal of Universal pharmacy and Life Sciences, 1, 61-70.

[13] Higgins, L.J. and Rutledge, J.C. (2009) Inflammation Associated with the Postprandial Lipolysis of Triglyceriderich Lipoproteins by Lipoprotein Lipase. Current Atherosclerosis Reports, 11, 199-205. https://doi.org/10.1007/s11883-009-0031-9

[14] Haugen, M., Brantsaeter, A.L., Trogstad, L., Alexander, J., Roth, C., Magnus, P. and Meltzer, H.M. (2009) Vitamin D Supplementation and Reduced Risk of Preeclampsia in Nulliparous Women. Epidemiology, 20, 720-726. https://doi.org/10.1097/EDE.0b013e3181a70f08

[15] Chiu, K.C., Chu, A., Go, V.L. and Saad, M.F. (2004) Hypovitaminosis D Is Associated with Insulin Resistance and Beta Cell Dysfunction. American Journal of Clinical Nutrition, 79, 820-825. https://doi.org/10.1093/ajcn/79.5.820

[16] Zeitz, U., Weber, K., Soegiarto, D.W., Wolf, E., Balling, R. and Erben, R.G. (2003) Impaired Insulin Secretory Capacity in Mice Lacking a Functional Vitamin D Receptor. The FASEB Journal, 17, 509-511. https://doi.org/10.1096/fj.02-0424fje

[17] Asemi, Z., Tabassi, Z., Heidarzadeh, Z., Khorammian, H., Sabihi, S.S. and Samimi, M. (2012) Effect of Calcium-Vitamin D Supplementation on Metabolic Profiles in Pregnant Women at Risk for Pre-Eclampsia: A Randomized Placebo-Controlled Trial. Pakistan Journal of Biological Sciences, 15, 316-324.

[18] Samimi, M., Kashi, M., Foroozanfard, F., Karamali, M., Bahmani, F., Asemi, Z., Hamidian, Y., Talari, H.R. and Esmaillzadeh, A. (2016) The Effects of Vitamin D plus Calcium Supplementation on Metabolic Profiles, Biomarkers of Inflammation, Oxidative Stress and Pregnancy Outcomes in Pregnant Women at Risk for Pre-Eclampsia. Journal of Human Nutrition and Dietetics, 29, 505-515. https://doi.org/10.1111/jhn.12339

[19] Holick, M.F. (2007) Vitamin D Deficiency. The New England Journal of Medicine, 357, 266-281. https://doi.org/10.1056/NEJMra070553

[20] Trinder, P. (1969) Determination of Glucose in Blood using Glucose Oxidase with an Alternative Oxygen Acceptor. Annals of Clinical Biochemistry, 6, 24-27.

[21] Trinder, P. (1969) Enzymatic Calorimetric Determination of Triglycerides by GOP-PAP Method. Annals of Clinical Biochemistry, 6, 24-27. https://doi.org/10.1177/000456326900600108

[22] Trinder, P. (1988) Report of the National Cholesterol Educational Program. Expert Panel on Detection, Evaluation and Treatment of High Blood Cholesterol in Adults. Archives of Internal Medicine, 148, 36-39. https://doi.org/10.1001/archinte.1988.00380010040006

[23] Lopes-Virella, M.F., Stone, P., Ellis, S. and Colwell, J.A. (1977) Cholesterol Deter- 
mination in High-Density Lipoproteins Separated by Three Different Methods. ClinChem, 23, 882-884.

[24] Friedewald, W.T., Levy, R.I. and Fredrickson, D.S. (1972) Estimation of the Concentration of Low-Density Lipoprotein Cholesterol in Plasma, without Use of the Preparative Ultracentrifuge. Clinical Chemistry, 18, 499-502.

[25] Phalak, P. and Tilak, M. (2012) Study of Lipid Profile in Pre-Eclampsia. Indian Journal of Basic \& Applied Medical Research, 2, 405-409.

[26] Vani, I., Gayathri, A., Nagamani, T. and Sunieeta, H. (2015) Lipid Profile Parameters in Normal and Preeclampsia Complicating Pregnancies-A Prospective Observational Study. The American Journal of Science and Medical Research, 1, 40-43.

[27] Mikhail, M.S., Basu, J., Palan, P.R., Furgiuele, J., Romney, S.L. and Anyaegbunam, A. (1995) Lipid Profile in Women with Preeclampsia: Relationship between Plasma Triglyceride Levels and Severity of Preeclampsia. Journal of the Association for Academic Minority Physicians, 6, 43-45.

[28] Hubel, C.A. (1998) Dyslipidemia, Iron, and Oxiditative Stress in Preeclampsia: Assessment of Maternal and Feto-Placental Interactions. Seminars in Reproductive Endocrinology, 16, 75-92.

[29] Gilbert, J.S., Ryan, M.J., LaMarca, B.B., Sedeek, M., Murphy, S.R. and Granger, J.P. (2008) Pathophysiology of Hypertension during Preeclampsia: Linking Placental Ischemia with Endothelial Dysfunction. American Journal of Physiology-Heart and Circulatory Physiology, 294, H541-H550.

https://doi.org/10.1152/ajpheart.01113.2007

[30] Sattar, N., Bendomir, A., Berry, C., Shepherd, J., Greer, I.A. and Packard, C.J. (1997) Lipoprotein Subfraction Concentrations in Preeclampsia: Pathogenic Parallels to Atherosclerosis. Obstetrics \& Gynecology, 89, 403-408. https://doi.org/10.1016/S0029-7844(96)00514-5

[31] Belo, L., Caslake, M. and Gaffney, D. (2002) Changes in LDL Size \& HDL Concentration in Normal and Preeclamptic Pregnancies. Atherosclerosis, 162, 425-432. https://doi.org/10.1016/S0021-9150(01)00734-1

[32] Cekmen, M.B. and Erbagci, A.B. (2003) Plasma Lipid and Lipoprotein Concentration in Pregnancy Induced Hypertention. Clinical Biochemistry, 36, 575-578. https://doi.org/10.1016/S0009-9120(03)00099-7

[33] Li, Y., Wang, C., Zhu, K., Feng, R.N. and Sun, C.H. (2010) Effects of Multivitamin and Mineral Supplementation on Adiposity, Energy Expenditure and Lipid Profiles in Obese Chinese Women. International Journal of Obesity, 34, 1070-1077. https://doi.org/10.1038/ijo.2010.14

[34] Jorde, R. and Grimnes, G. (2011) Vitamin D and Metabolic Health with Special Reference to the Effect of Vitamin D on Serum Lipids. Progress in Lipid Research, 50, 303-312. https://doi.org/10.1016/j.plipres.2011.05.001

[35] Vaskonen, T., Mervaala, E., Sumuvuori, V., Seppanen-Laakso, T. and Karppanen, H. (2002) Effects of Calcium and Plant Sterols on Serum Lipids in Obese Zucker Rats on a Low-Fat Diet. The British Journal of Nutrition, 87, 239-245. https://doi.org/10.1079/BJN2001508

[36] Cho, H.J., Kang, H.C., Choi, S.A., Ju, Y.C., Lee, H.S. and Park, H.J. (2005) The Possible Role of $\mathrm{Ca}^{2+}$ on the Activation of Microsomal Triglyceride Transfer Protein in Rat Hepatocytes. Biological and Pharmaceutical Bulletin, 28, 1418-1423. https://doi.org/10.1248/bpb.28.1418

[37] Zittermann, A., Frisch, S., Berthold, H.K., Gotting, C., Kuhn, J., Kleesiek, K., et al. (2009) Vitamin D Supplementation Enhances the Beneficial Effects of Weight Loss 
on Cardiovascular Disease Risk Markers. The American Journal of Clinical Nutrition, 89, 1321-1327. https://doi.org/10.3945/ajcn.2008.27004

[38] Devaraj, S., Jialal, G., Cook, T., Siegel, D. and Jialal, I. (2011) Low Vitamin D Levels in Northern American Adults with the Metabolic Syndrome. Hormone and Metabolic Research, 43, 72-74. https://doi.org/10.1055/s-0030-1268485

[39] Gagnon, C., Lu, Z.X., Magliano, D.J., Dunstan, D.W., Shaw, J.E., et al. (2012) Low Serum 25-Hydroxyvitamin D Is Associated with Increased Risk of the Development of the Metabolic Syndrome at Five Years: Results from a National, Population-Based Prospective Study (The Australian Diabetes, Obesity and Lifestyle Study: AusDiab). The Journal of Clinical Endocrinology \& Metabolism, 97, 1953-1961. https://doi.org/10.1210/jc.2011-3187

[40] Weisberg, S.P., McCann, D., Desai, M., Rosenbaum, M., Leibe, R.L. and Ferrante Jr., A.W. (2003) Obesity Is Associated with Macrophage Accumulation in Adipose Tissue. The Journal of Clinical Investigation, 112, 1796-1808.

https://doi.org/10.1172/JCI200319246

[41] Von Hurst, P.R., Stonehouse, W. and Coad, J. (2010) Vitamin D Supplementation Reduces Insulin Resistance in South Asian Women Living in New Zealand Who Are Insulin Resistant and Vitamin D Deficient: A Randomised, Placebo-Controlled Trial. British Journal of Nutrition, 103, 549-555. https://doi.org/10.1017/S0007114509992017

[42] Schleithoff, S.S., Zittermann, A., Tenderich, G., Berthold, H.K., Stehle, P. and Koerfer, R. (2006) Vitamin D Supplementation Improves Cytokine Profiles in Patients with Congestive Heart Failure: A Double-Blind, Randomized, Placebo-Controlled Trial. The American Journal of Clinical Nutrition, 83, 754-759. https://doi.org/10.1093/ajcn/83.4.754

[43] Pikilidou, M.I., Lasaridis, A.N., Sarafidis, P.A., Befani, C.D. and Koliakos, G.G. (2009) Insulin Sensitivity Increase after Calcium Supplementation and Change in Intraplatelet Calcium and Sodium-Hydrogen Exchange in Hypertensive Patients with Type 2 Diabetes. Diabetic Medicine, 26, 211-219.

https://doi.org/10.1111/j.1464-5491.2009.02673.x 